\title{
Management of Focal Chondral Lesion in the Knee Joint
}

\author{
Seung-Suk Seo, MD, PhD, Chang-Wan Kim, MD, PhD and Dae-Won Jung, MD \\ Department of Orthopaedics, Busan Paik Hospital, College of Medicine, Inje University, Busan, Korea
}

\begin{abstract}
Articular cartilage does not contain vascular, nervous and lymphatic tissue and chondrocytes hardly participate in the healing or repair process of chondral tissue because of being surrounded by plenty of extracellular matrix. Therefore, the injury to articular cartilage frequently requires an operative treatment. The goal of surgical repair of articular cartilage is to regenerate nearly normal chondral tissue and prevent degenerative arthritis caused by the articular cartilage defect. Microfracture is a kind of cartilage repair procedure that makes a fibrin clot containing mesenchymal stem cells in the chondral lesion. Microfracture is a simple procedure but it has a disadvantage that the repaired tissue is fibrocartilage. Autologous chondrocyte implantation has an advantage that it implants fully differentiated chondrocytes to the lesion, which theoretically produces hyaline cartilage. Its disadvantages are that it is a two stage and a costly procedure. Osteochondral autograft transplantation is a one stage procedure and repairs the lesion with hyaline cartilage. But its limitation is the lack of donor site availability. Surgeons who understand the theoretical background, indications, surgical methods, rehabilitation, complications, and clinical course of cartilage repair procedures can achieve the goal of preventing degenerative arthritis.
\end{abstract}

Key words: Knee joint, Articular cartilage, Focal chondral lesion, Management.

\section{Introduction}

Articular cartilage is devoid of vascular, nervous and lymphatic tissue and chondrocytes are unable to participate in the healing or repair process of damaged tissue because of extracellular matrix that surrounds the cartilage cells. About 200 years ago,

Received September 20, 2011; Revised (1st) October 10, 2011; (2nd) October 24, 2011; Accepted October 26, 2011.

Correspondence to: Seung-Suk Seo, MD, PhD.

Department of Orthopaedics, Inje University Busan Paik Hospital, Inje University College of Medicine,

633-165 Gaegeum 2-dong, Busanjin-gu, Busan 614-735, Korea.

Tel: +82-51-890-6255, Fax: +82-51-892-6619

Email: wellknee@gmail.com

*This study was supported by a grant of the Korea Healthcare

Technology R\&D Project, Ministry for Health, Welfare \& Family Affairs, Republic of Korea (A084120). This work was supported by Grant from Inje University, 2009.

This is an Open Access article distributed under the terms of the Creative Commons Attribution Non-Commercial License (http://creativecommons.org/licenses/by-nc/3.0/) which permits unrestricted non-commercial use, distribution, and reproduction in any medium, provided the original work is properly cited.

Copyright ( $\odot$ 2011. KOREAN KNEE SOCIETY

www.jksrr.org a Scottish doctor, William Hunter, documented that chondral lesions had been considered difficult to treat and heal from the time of Hippocrates. In cases where chondral defects involve the subchondral bone causing bleeding, mesenchymal stem cells or fibroblasts promote repair with fibrocartilage. Unfortunately, fibrocartilage is biomechanically inferior to hyaline cartilage and eventually results in osteoarthritis ${ }^{1,2)}$. Therefore, the goal of treatment for articular cartilage defects is to regenerate hyaline-like cartilage to prevent osteoarthritis ${ }^{3)}$. Total knee replacement can be helpful for patients with advanced age and severe osteoarthritis, but there are only a few options for young osteoarthritic patients. For successful focal chondral defect treatment, the prevalence of articular cartilage damage, structures and characteristics of the articular cartilage, post-injury responses, and scientific bases and clinical outcomes of various treatment methods should be well understood.

\section{Treatments}

The goal of focal chondral defect treatment is to enable patients to return to normal activities or active lifestyle through pain relief and joint function improvement. The treatment decision should be based on the patient's activity level, age, cause, size and depth 
of defects, and presence of combined defects. Available treatment options include conservative treatment, surgical treatment for symptom relief or articular cartilage restoration.

\section{Conservative Treatment}

Conservative treatment for chondral defects of the knee can be effective for pain relief, but it cannot be used for articular cartilage restoration. Craig et al. ${ }^{4}$ suggested that conservative treatment can be an option when mild pain is present or the risk of surgery is greater than its benefit. Messner and Maletius ${ }^{5}$ followed up 28 patients with isolated chondral damage of the knee for 14 years and concluded that conservative treatment was not helpful in preventing the progress of the damage: the patients had excellent or good clinical results, but radiographic examination revealed abnormal findings in $\geq 50 \%$ of the patients. Conservative treatment includes the use of non steroid anti inflammatory drugs (NSAIDs), pain killers, hormones (estrogen and growth hormone), chondroprotective agents (glucosamine \& chondroitin phosphate and omega-3), intraarticular injections of steroids or hyaluronic acid, weight loss to reduce the load on the knee joint, braces, and physical treatment. Unfortunately, these methods can be useful for symptom relief only not for restoring structural integrity of the articular cartilage $e^{6)}$.

\section{Surgical Treatment}

The purpose of surgical treatment is to improve symptoms and prevent degenerative changes by achieving structural and biomechanical restoration of the articular cartilage. Surgical treatment methods can be broadly divided into arthroscopic lavage and debridement, cell-based therapy (subchondral bone stimulation for chondral tissue differentiation or culture and implantation of chondrocytes), and tissue-based therapy (osteochondral autograft transplantation or osteochondral allograft transplantation). The advantages/disadvantages of each method, size, location, and depth of a lesion, and the patient's age and activity level should be assessed to determine an appropriate treatment method. However, the two most important factors that should be considered are the cause and characteristics of chondral defects. Chondral lesions can be either focal or degenerative. For the treatment of focal lesions, sufficient debridement should be performed to maintain the adjacent area in the articular cartilage healthy for successful structural and biomechanical restoration. In contrast, for degenerative lesions where the defective and transitional area is wide, a sufficient debridement may restrict subsequent treatment options or cause unfavorable results. In addition, poor cell/tissue regeneration ability may result in less than satisfactory outcome after surgery. Therefore, the cause and characteristics of chondral lesions should be taken into consideration in performing surgical treatment.

\section{1) Arthroscopic lavage and debridement}

There has been a transition from open to arthroscopic lavage and debridement of chondral lesions. Arthroscopic lavage is to remove inflammatory mediators that may be responsible for joint effusion and loose cartilage and collagen debris. Debridement of articular cartilage (chondroplasty) is a procedure for removing unstable cartilage fragments or margins of the cartilage that may cause joint impingement with a curette or a shaver in order to alleviate joint pain and prevent additional articular cartilage destruction. Jackson et al. ${ }^{7)}$ observed clinical improvements in $80 \%$ of their patients at 3.5 years after arthroscopic debridement and correlated degenerative changes with clinical outcome. However, Kirkley et al. ${ }^{8)}$ reported that arthroscopic surgery for knee cartilage defects provided no additional benefit to optimized physical or medical therapy. Arthroscopic repair can be helpful for preventing the progress of delamination of articular cartilage, but there is controversy over its influence on the long-term longevity of the articular cartilage.

\section{2) Cell-based therapy}

Cell-based therapy is a promising approach using the patient's own cells for the treatment of chondral defects. There are marrow stimulating procedures and autologous chondrocyte implantation (ACI). Marrow stimulating procedures include abrasion arthroplasty, drilling, and microfracture. However, the former two are currently rarely performed because they have been associated with poor clinical outcome.

\section{(1) Microfracture}

Microfracture is an articular cartilage repair technique in which tiny fractures are made 2-4 $\mathrm{mm}$ apart from each other to cause bleeding in the subchondral bone and fibrin clots in the perforations release mesenchymal stem cells that would differentiate into chondrocytes ${ }^{9)}$.

Multi-potential mesenchymal stem cells can differentiate into fibrocartilage cells and chondrocytes and induce fibrocartilage or hyaline-like cartilage formation. Fibrocartilage contains more collagen and less proteoglycans compared to hyaline cartilage. It is composed of more type I collagen than type II collagen. Type I collagen has lower compressive strength, elasticity, and wear resistance compared to type II collagen. Accordingly, fibrocartilaginous repair eventually results in failure 
under repeated mechanical stress. In addition, the number of mesenchymal stem cells is small and tends to decrease over time ${ }^{10)}$. In spite of these disadvantages, microfracture has become a preferred procedure because it does not cause damage to other normal regions and is easy to perform and relatively economical.

Microfracture can be used for unstable or full-thickness (Outerbridge grade 3 or 4) focal chondral defects or degenerative arthritis with good knee alignment. The procedure is contraindicated for patients with inflammatory arthritis, lower limb malalignment, partial-thickness (Outerbridge grade 1 or 2) chondral defects, or reluctance to participate in rehabilitation. There are other considerations that should be taken into account. The older the patient is, the poorer the treatment outcome. Traumatic lesions have been associated with better treatment results compared to degenerative lesions. Theoretically, microfracture can be performed regardless of the size of a lesion. However, Steadman et al. ${ }^{11)}$ described that lesions larger than $400 \mathrm{~mm}^{2}$ responded worse to the treatment. In addition, the higher the body mass index, the poorer the treatment outcome. The procedure consists of debridement and drilling. Debridement should be performed thoroughly. All loose cartilage should be completely removed to make the lesion surrounded by healthy cartilage and form perpendicular edges to create a well shouldered lesion (Fig. 1).
This is intended to make marrow clots firmly adhere to the lesion and reduce direct load across the lesion for stable recovery. The remaining calcified cartilage layer should be completely removed because it inhibits attachment of repair tissue ${ }^{12)}$. During this procedure, care should be taken to avoid excessive damage to the subchondral bone. Subchondral bone drilling should be performed in a centripetal manner from the margin to the center of the lesion. Microfracture holes should be placed 3-4 mm apart from each other and 4-5 mm in depth (Fig. 1) ${ }^{13)}$. An appropriate depth can be determined by observing fat droplets that is released from the marrow through the microfracture holes while controlling the perfusion pressure (Fig. 1).

Different postoperative rehabilitation regimens are adopted according to the location of a lesion. For femorotibial joint lesions, continuous passive motion exercise is initiated immediately after surgery. Steadman et al. ${ }^{14)}$ reported that full passive range of motion could be obtained after 6 to 8 weeks of toe touch weight bearing and continuous passive motion exercise that had been started immediately after surgery. For femoropatellar joint lesions, care should be taken not to apply shear force on the lesions using a brace that allows for 0-20 degrees of joint movement. On the other hand, Marder et al. ${ }^{15)}$ suggested that postoperative physical treatment or weight bearing does not
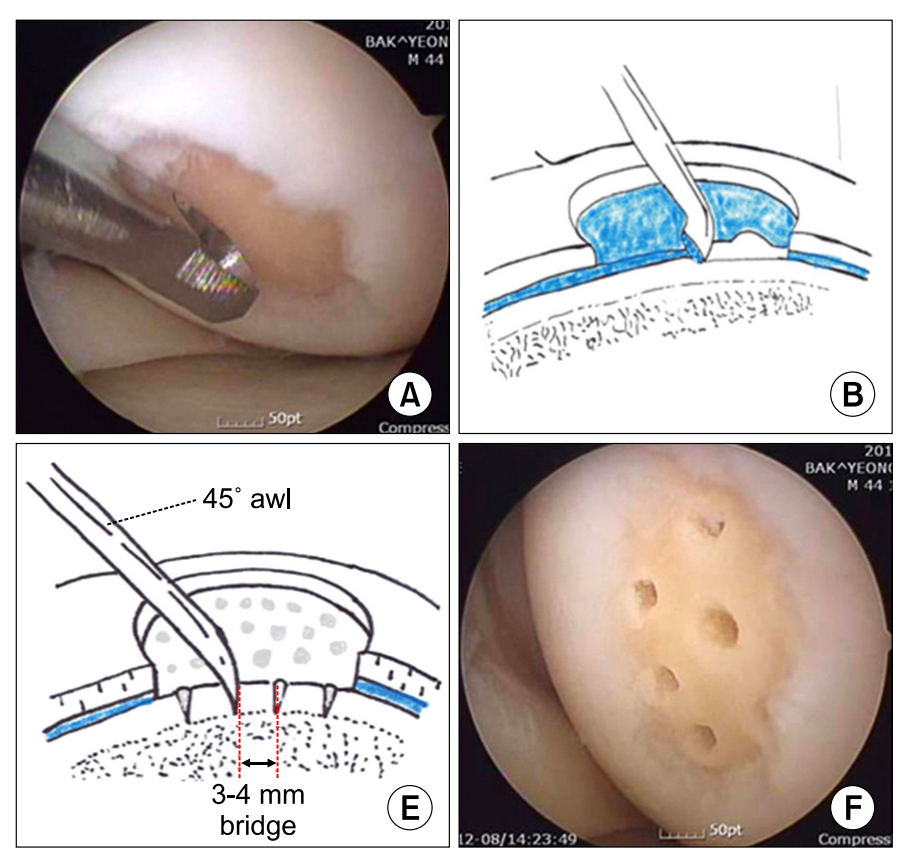
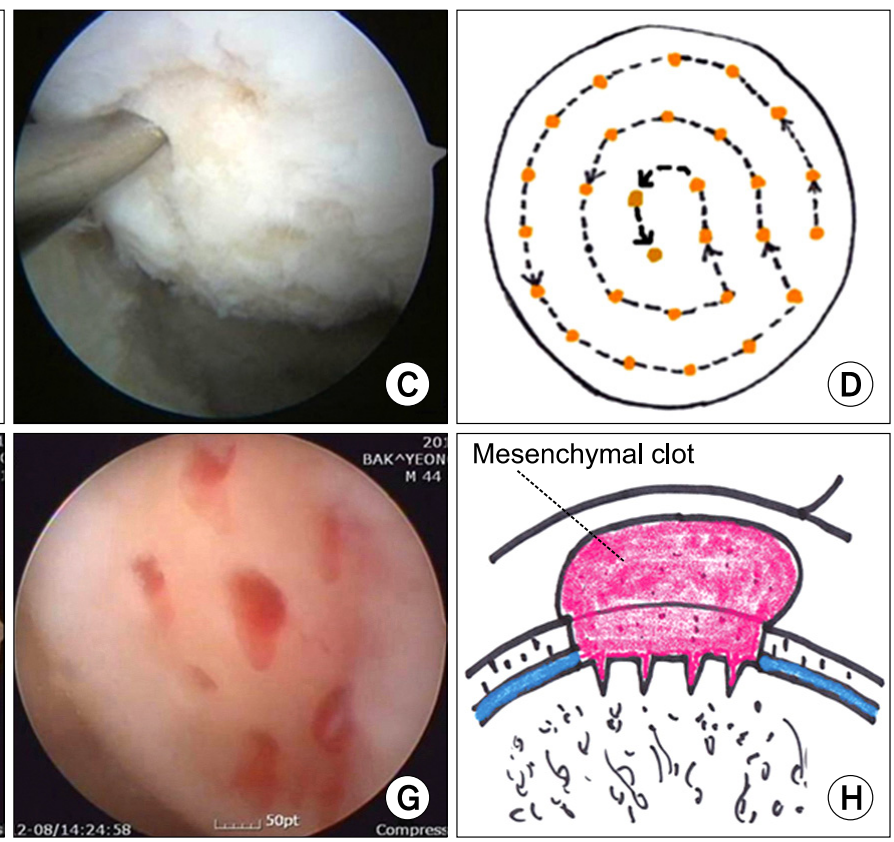

Fig. 1. Surgical procedure of microfracture. (A) Unstable cartilage flap and calcified cartilage bed is debrided with open curette. (B) It is important to debride the calcified cartilage layer and make a well-contained pocket surrounded healthy cartilage (well-shouldered). (C) Subchondral bone is punctured with an awl. (D) Microfracture is circumferentially performed from periphery to center. (E) The penetration of subchondral bone is 3 to $4 \mathrm{~mm}$ deep and apart. (F) Arthroscopic photograph showing the final step of microfracture. (G) Mesenchymal blood egress from bone marrow through subchondral holes. $(\mathrm{H})$ It is important for tissue regeneration to keep the mesenchymal clot in the defect. 
have to be avoided when lesions are "well shouldered" during operation because the repair tissue is not affected by weigh bearing based on their observation that aggressive physical treatment did not influence the treatment outcome.

In summary, various studies have shown that microfracture can be helpful in improving overall symptoms of chondral defects, but the symptoms worsen over time and poor clinical outcome can be attributed to advanced age, large lesion size, and high activity level $^{16-19)}$.

\section{(2) Autologous chondrocyte implantation}

ACI is a two-stage procedure in which chondrocytes harvested from a non-weight bearing portion of the articular cartilage are implanted into a defect. Compared to other treatment methods for chondral defects, ACI causes less damage to the subchondral bone plate and trabecula, can be performed on larger lesions, does not cause donor-site discomfort or complications, and is relatively easy to perform. However, the procedure requires joint excision, should be done in two separate steps, and involves a long rehabilitation period ${ }^{20)}$.

The best candidates for ACI are patients who are between 15 and 55 years of age with full-thickness (Outerbridge stage 3 or 4) focal chondral defects or unstable osteochondritis dissecans. Procedures for lower limb malalignment or ligament instability can precede ACI if necessary. The ideal lesion size for the procedure is 2 to $10 \mathrm{~cm}^{2}$. In case of osteochondral lesions, ACI can be performed for lesions that are $6-8 \mathrm{~mm}$ in depth and bone grafting should precede ACI for deeper lesions. Although ACI can be performed regardless of the location of a lesion in the knee, best clinical results can be expected for lesions in the femoral condyle. ACI is contraindicated for patients who are not cooperative with postoperative rehabilitation or who have inflammatory arthritis or a kissing lesion (Outerbridge stage 3 or 4 lesion on the opposing articular surface).

The first stage of ACI involves an arthroscopic inspection of the focal lesion to assess the size, depth, and potential bone loss. Lesions 6 to $8 \mathrm{~mm}$ deeper than the subchondral bone may require bone grafting prior to ACI. The opposing surface of the cartilage defect should also be examined. An Outerbridge stage 1 or 2 lesion on the opposing surface can be considered a relative contraindication to ACI. Next, chondrocytes should be harvested using gouges or curettes from a low weight bearing area of the knee including the lateral margin of the intercondylar notch or the superomedial trochlea of the femur. The approximate size of the biopsy should be 200-300 mg. The subchondral bone should be penetrated to allow a fibrocartilage repair of the donor site. The second stage of the procedure is performed 4 weeks after the biopsy when sufficient cells are cultured. The surgical site depends on defect location with use of a medial or lateral parapatellar mini-arthrotomy. All unstable or damaged cartilage is removed to make the lesion surrounded by stable and healthy cartilage that forms vertical walls to create a wellshouldered lesion. The neighboring cartilage should be 2 to $3 \mathrm{~mm}$ thick to accommodate suture fixation of the periosteal graft. The lesion should be debrided to be in a circular or an oval shape to facilitate tight suturing of the graft. The calcified layer in the bed of the lesion is removed and the subchondral bone is exposed. During this procedure, care should be taken to avoid subchondral bone damage that would cause bleeding from bone marrow and contamination of the transplanted chondrocytes with undifferentiated cells. Subsequently, a periosteal flap that will cover the cartilage defect should be harvested from the proximal medial tibia or a site distal to the pes anserine insertion. The fibrous tissue and fat of the periosteum should be removed. Using a template made of aluminum foil or paper, the size of the defect is measured. The periosteal flap should be larger than the lesion by 1 to $2 \mathrm{~mm}$ and care should be taken not to penetrate it. The flap is sutured to the cartilage with the cambium layer facing the defect using a 6-0 absorbable suture. Closely spaced sutures should be performed leaving an opening in the most superior portion of the lesion for the injection of chondrocytes with an 18-guage angiocatheter. The injection should be performed carefully from the bottom upwards to ensure even distribution of the chondrocytes throughout the lesion. The opening is closed with suture and sealed with fibrin glue (Fig. 2).

Rehabilitation after ACI is a long and challenging process because it is a cell-based therapy as microfracture. Rehabilitation protocols vary according to the location of a lesion and condition of the surgical site. Weight-bearing or movement of the knee is restricted for 12 to 18 hours after surgery until the chondrocytes are embedded within the articular cartilage. Joint exercise using a continuous passive motion (CPM) machine is performed 6 to 8 hours per day for the first four postoperative weeks. For the first two postoperative weeks, weight-bearing is avoided. Between the second and fourth postoperative week, 10-20 kg of weight bearing is allowed and between the fourth and sixth postoperative week, walking with the aid of a crutch is allowed. Weight-bearing is progressed over the 12 postoperative weeks to full weight bearing. Until the second postoperative week, the knee should be immobilized in a brace in full extension except when a CPM or joint exercise is performed. The range of motion should be increased gradually with use of a CPM machine $e^{21)}$. 

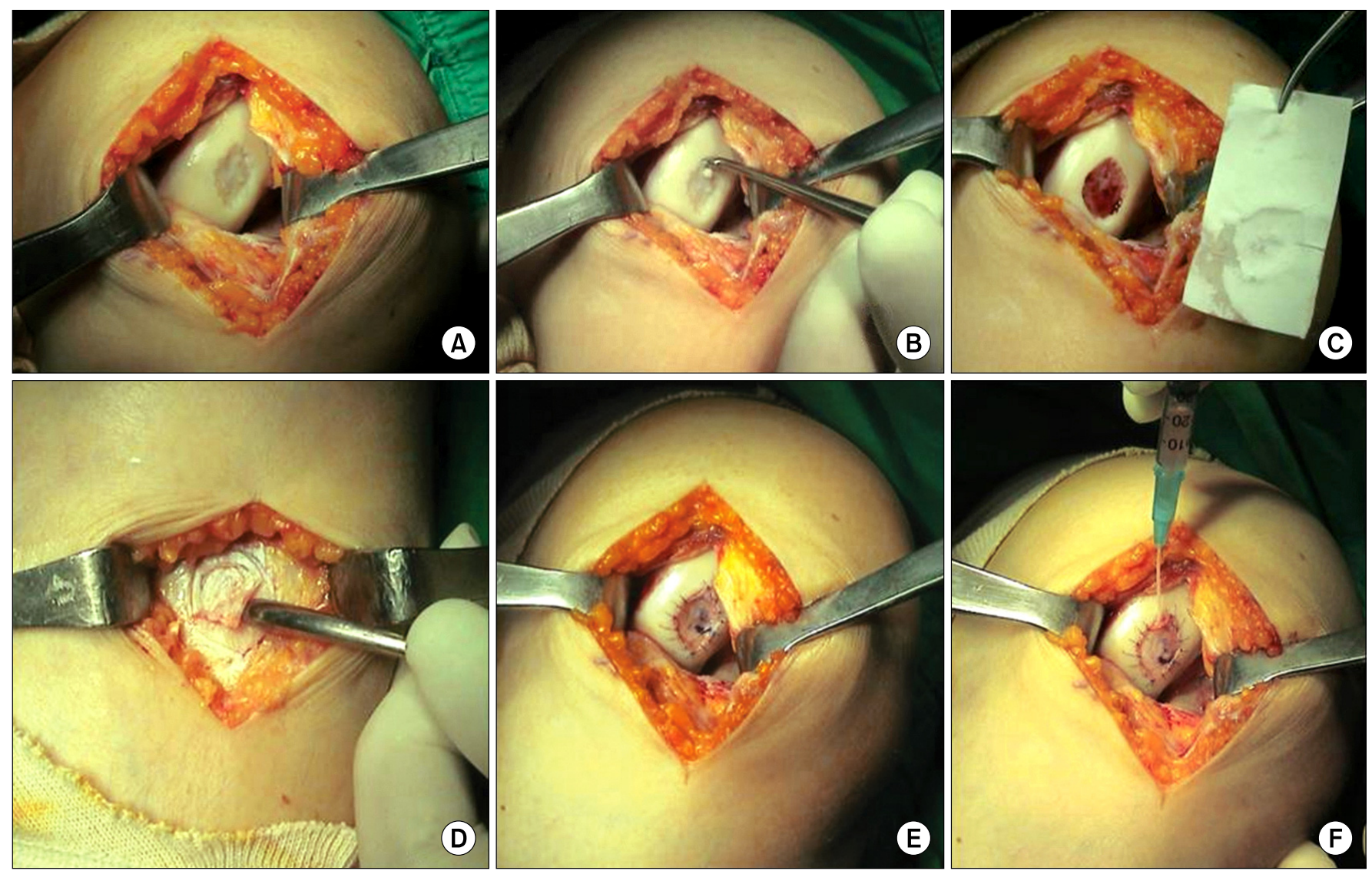

Fig. 2. Surgical procedure of the 1st generation autologous chondrocyte implantation. (A) Outerbridge 4 lesion in the medial femoral condyle. (B) Debridement of the calcified cartilage layer and unstable chondral flap. (C) Defect size is measured with a sterile paper. A $2 \mathrm{~mm}$ oversized template is needed. (D) Periosteal flap is excised from the proximal medial tibia. (E) The periosteal flap watertightly covers the defect. (F) Chondrocyte suspension is injected to the defect through a plastic 18-gauge angiocath needle.

Peterson et al. ${ }^{22)}$ observed good to excellent results in 50 out of 61 patients at two years after ACI and in 51 out of 60 patients at eleven years after ACI. A second-look arthroscopy showed a normal appearance of the cartilage in $90 \%$ of the 8 patients and hyaline cartilage was confirmed by histological examination in most of the patients. Factors that could influence the outcome of ACI have also been addressed in many studies. Minas et $\mathrm{al}^{23)}$ reported that prior procedures using marrow stimulating techniques such as microfracture increase the failure rates of ACI. Mithoefer et al. ${ }^{24)}$ observed poor clinical results in patients with large or multiple cartilage lesions. Saris et al. ${ }^{25)}$ documented that the longer the duration of symptoms before ACI was, the poorer the clinical results. Knutsen et al. ${ }^{26)}$ noted that patients under 30 years of age with high activity had good clinical results after ACI. These studies indicate that various factors should be taken into consideration to achieve satisfactory outcome after the procedure.

The first generation ACI has often been associated with periosteal complications. Kreuz et al. ${ }^{27)}$ reported that clinical improvement was observed in most of the patients after ACI, but MRIs revealed periosteal hypertrophy in $28 \%$ of the total patients and in $50 \%$ of the patients with ACI for chondral defects in the knee. Seo et al. ${ }^{28)}$ reported that ACI for chondral defects of the femoral condyle resulted in clinical improvement, but the International Cartilage Repair Society (ICRS) assessment revealed abnormal findings in $60 \%$ and graft hypertrophy in $21 \%$ of the patients (Figs. 3, 4).

The first generation ACI has been replaced by the second and then the third generation ACI to prevent periosteal complications and obtain structurally and biomechanically superior tissue. The second generation ACI is a procedure in which a synthetic collagen membrane instead of a periosteal flap is sutured to the defect and chondrocytes are injected. The third generation ACI is a procedure in which chondrocytes are cultured in a biodegradable scaffold that will be implanted in the defect. Although various studies have addressed the results 

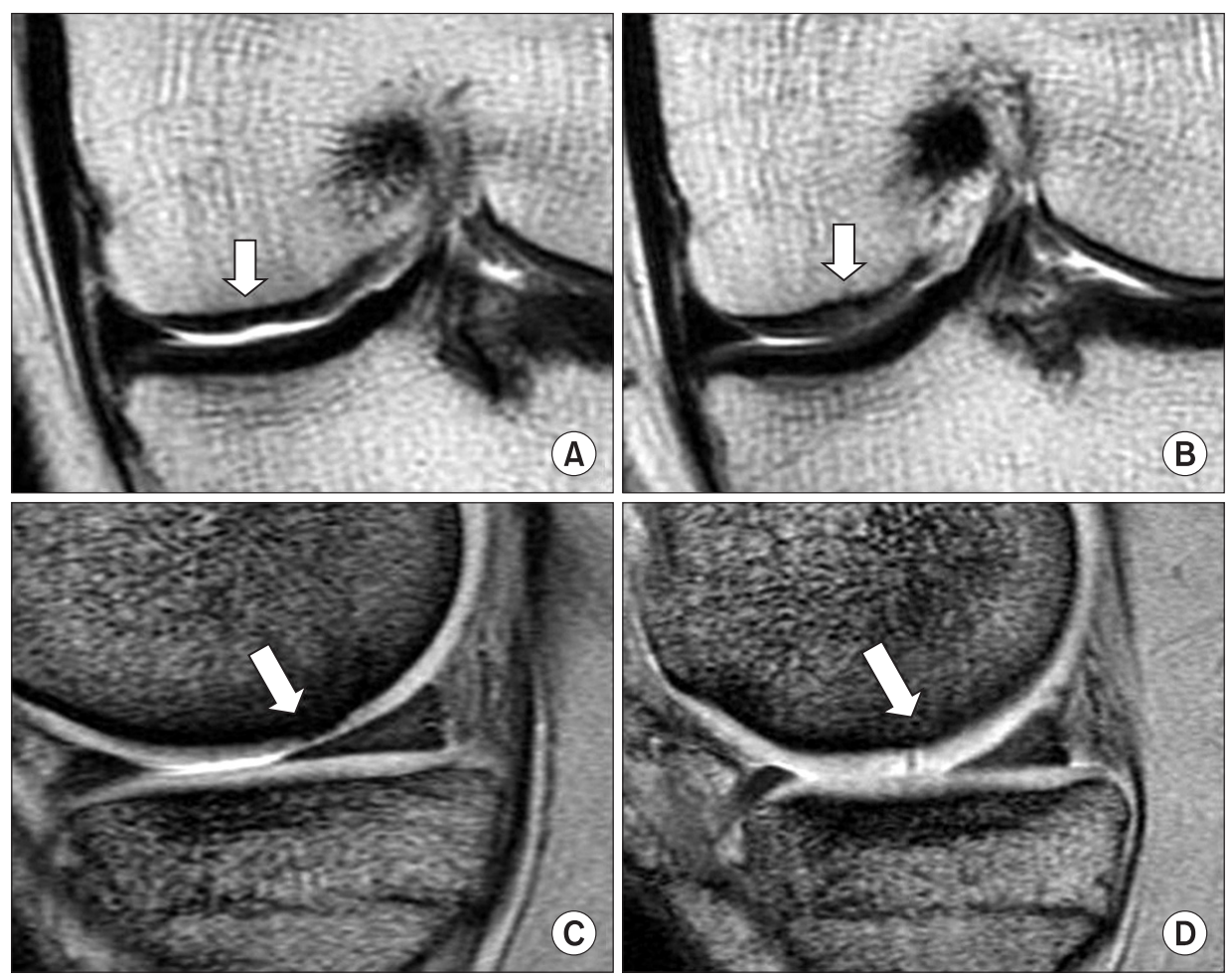

Fig. 3. MRI findings before and after autologous chondrocyte implantation (ACI). (A) Coronal proton density image showing the focal chondral defect with thinning of the cartilage. (B) Coronal proton density image showing the slightly hyperintense repaired tissue at 26 months after ACI. (C) Sagittal T2 fast spin echo (FSE) image showing the thinning of the cartilage and irregular elevation of the subchondral bone plate. (D) Sagittal T2 FSE image showing the hypertrophied regenerated cartilage tissue with focal hyperintense area at 26 months after ACI.
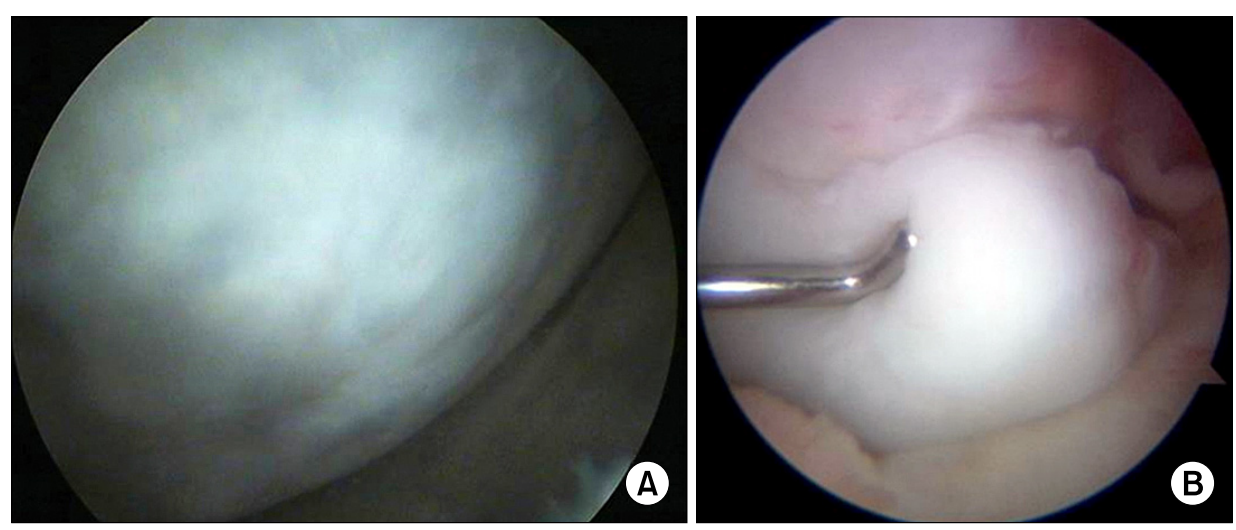

Fig. 4. Second look arthroscopic findings after autologous chondrocyte implantation (ACI). (A) Regenerated hyaline like tissue after ACI, of which surface shows a smooth and well-incorporated margin. (B) Graft hypertrophy after 1 st generation ACI, which causes a locking of the knee. of each procedure, more studies should follow to confirm those results $^{29-35)}$.

ACI is useful for maintaining good clinical outcome for a long-term period in cases of focal cartilage defects, but the disadvantages include that it requires two separate procedures for chondrocyte collection and implantation and joint excision is unavoidable in most cases during implantation. With the advent of the second and third generation ACI technique, the procedure can be performed arthroscopically and has become easier to perform. We expect further improvements will be made in the future.
3) Tissue-based therapy

Tissue-based therapy includes osteochondral autograft transplantation, osteocondral allograft transplantation, and tissue engineered scaffold implantation. The advantages of these procedures are treating defects in one stage, promoting rapid return to daily living activities and sports with use of biomechanically healthy tissue, and maintaining postoperative results for a long-term period due to hyaline cartilage repair. Since tissue engineered scaffold implantation can be used in limited clinical settings and accordingly only a small number of clinical results have been reported, we describe the former two methods in this review article. 
(1) Osteochondral autograft transplantation (OAT, mosaicplasty)

OAT can be a solution for hyaline repair of chondral defects. The advantages of this technique include: 1 ) it is a one-stage procedure unlike ACI; 2) it can be performed arthroscopically for small lesions; 3 ) osteochondral plugs can be obtained with ease; 4) it is a tissue-based therapy that allow earlier rehabilitation compared to cell-based therapy; 5) it can be performed at a lower cost compared to ACI; 6) the lesion is covered by hyaline cartilage; and 7) it results in few complications. One of the disadvantages of the procedure is that it cannot be applied for large lesions due to limited donor site availability. For large lesions, multiple osteochondral plugs are necessary, but it is difficult to coordinate the height and direction of the implanted osteochondral plugs with the adjacent native cartilage. The gaps between osteochondral plugs and between the plugs and the surrounding cartilage are filled with fibrocartilage. In addition, posttraumatic arthritis may develop in the patellofemoral joint due to graft harvest.

The primary indication for $\mathrm{OAT}^{36)}$ is a symptomatic anterior cartilage defect (Outerbridge stage 3 or 4 ) that is $1.0-4.0 \mathrm{~cm}^{2}$ in size in patients less than 45 years of age. The contraindications include patients above 50 years of age, larger than $8.0 \mathrm{~cm}^{2}$ lesions, moderate or severe osteoarthritis, inflammatory arthritis, lack of appropriate donor site, and noncompliance with rehabilitation. Besides, lower limb alignment and combined ligament injuries should also be assessed and treated prior to OAT.

The procedure consists of defect preparation, graft harvesting with a tubular chisel and graft removal from the chisel, and transplantation of the graft ${ }^{36)}$. On defect preparation, unstable cartilage is removed and the size of a lesion is measured to determine the size, number, and arrangement of osteochondral plugs. The most common donor sites are the superolateral aspect of the femoral intercondylar notch and the medial/lateral margin of the femoral trochlea. The osteochondral plug can be harvested using a tubular chisel and the appropriate length is $15 \mathrm{~mm}^{37)}$. It is important to direct the tubular chisel perpendicular to the articular surface to obtain a graft that has a level articular surface. The graft is ejected from the chisel by tapping the osseous tissue, not the articular surface. Next is the transplantation of the osteochondral plug into the defect, which consists of drilling, dilation, and delivery. An appropriately sized drill guide is placed perpendicular to the walls of the lesion and the same diameter drill bit is introduced to create a tunnel in the lesion. The tunnel
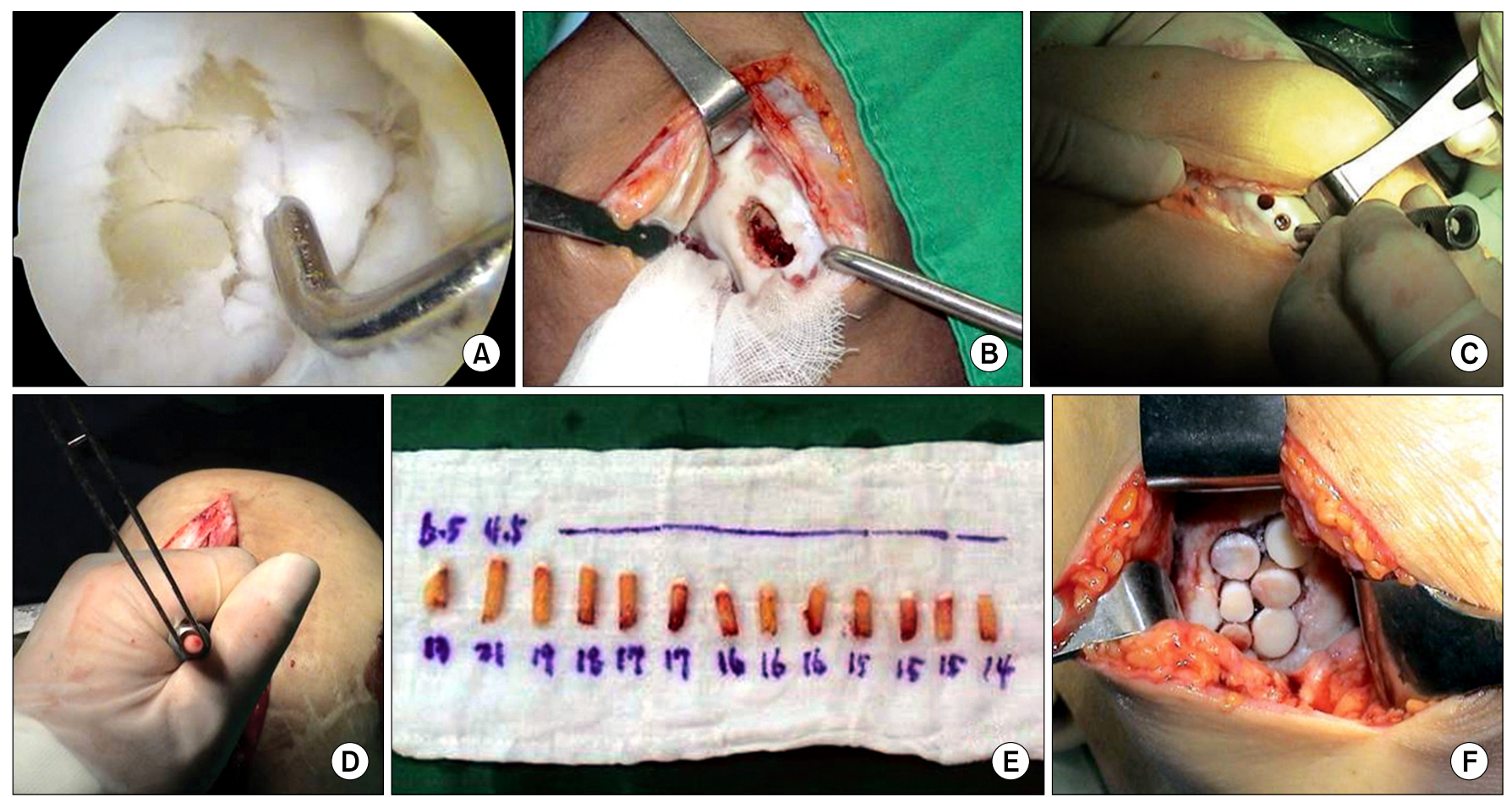

Fig. 5. Surgical procedure of osteochondral autograft transplantation. (A) Arthroscopic determination of the number and size of grafts needed after debridement of cartilage lesion. (B) Open procedure. (C) Harvesting the osteochondral plug with a tubular chisel from the lateral supracondylar ridge. The tubular chisel must be perpendicularly located to the chondral surface. (D) Introduction of the osteochondral plug through a drill guide. (E) Harvested osteochondral plugs. Size and length of plugs are marked on the wet gauze. (F) Focal cartilage defect reconstructed with multiple osteochondral plugs. It is important to make a congruent surface with the adjacent cartilage. 

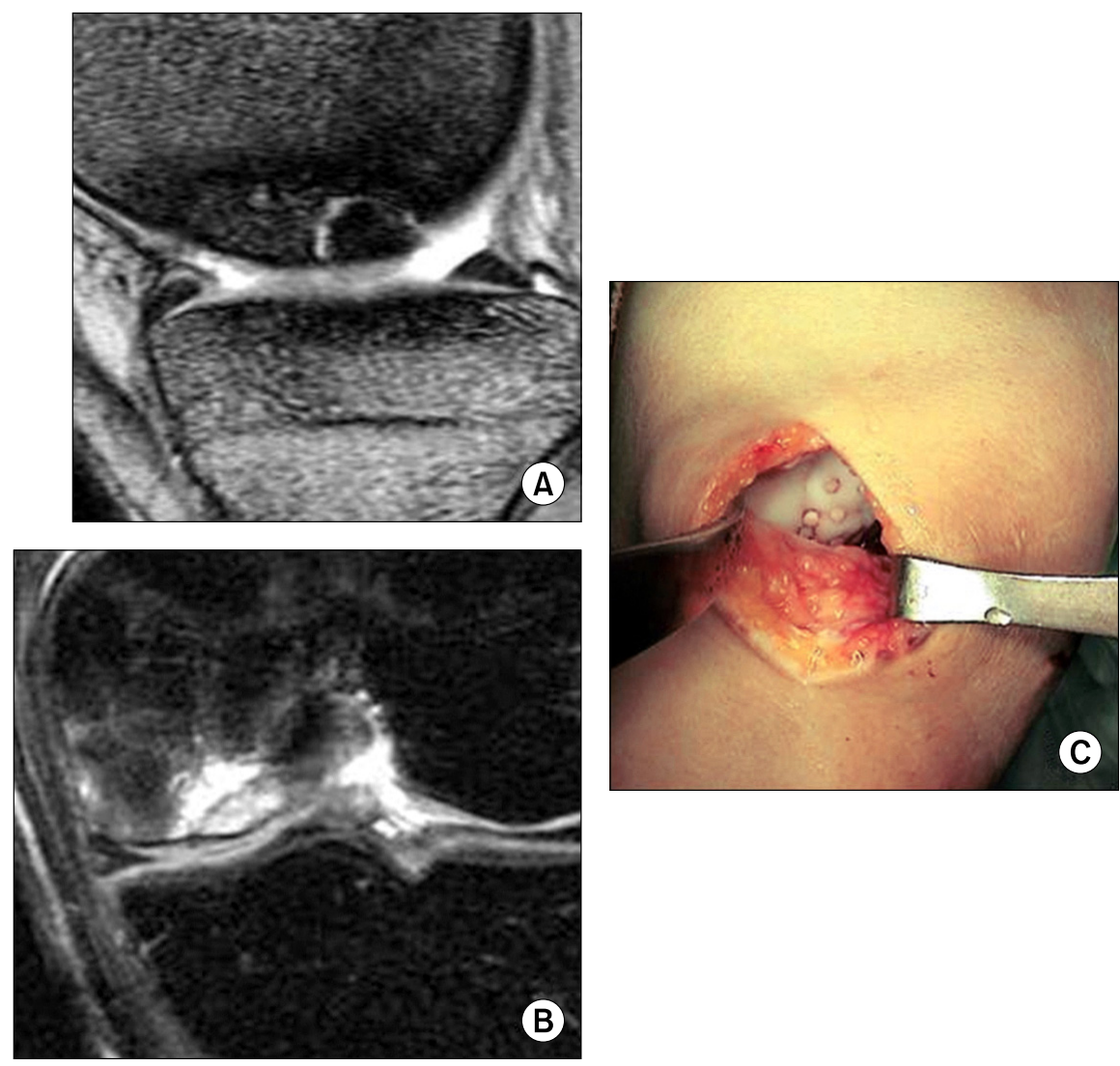

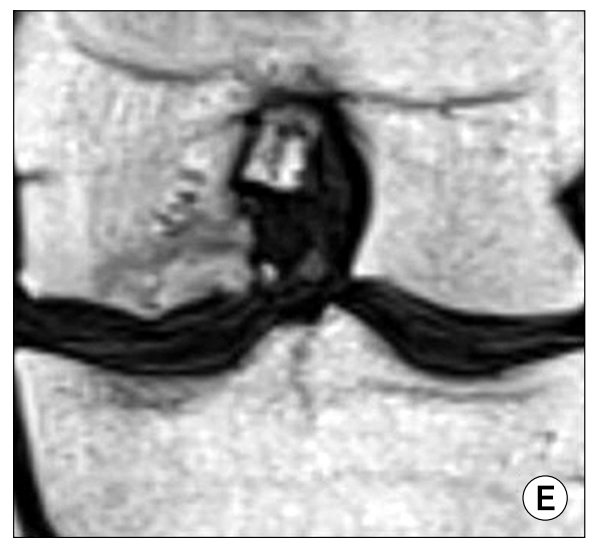

Fig. 6. Osteochondral plug fixation for the treatment of osteochondritis dissecans (OCD). (A) Sagittal T2 fast spin echo (FSE) image showing stage 3 OCD lesion in the medial femoral condyle. The lesion is partially separated. (B) Coronal T2 fat suppression FSE image showing OCD lesion with focal bone marrow edema. (C) Fixation of OCD with multiple osteochondral plugs. (D) Sagittal image. (E) Coronal image showing the OCD lesions completely incorporated to the host bone at 24 months after surgery.

should be approximately $2 \mathrm{~mm}$ longer than the graft length and widened with a dilator of the same diameter. The graft is gently tapped into the hole using a delivery tamp to avoid chondrocyte death $^{38)}$. When several grafts need to be implanted, the procedure is repeated for each graft to increase mechanical stability. It is crucial to ensure that the articular surface of the graft is level with the adjacent articular surface (Fig. 5). In a biomechanical study conducted by Koh et al. ${ }^{39}$, when a graft was placed slightly deeper than the adjacent articular cartilage, the contact pressure was normal, whereas $2 \mathrm{~mm}$ elevation of a graft resulted in an approximately $50 \%$ increase in the pressure ${ }^{39)}$. In an animal study, cartilage necrosis and fibrous overgrowth were observed when grafts were placed $2 \mathrm{~mm}$ deeper than the adjacent articular cartilage $^{40)}$.

OAT allows rapid rehabilitaiton ${ }^{36)}$. Continuous passive motion and straight leg raising are performed immediately after surgery. Weight bearing is allowed depending upon the number of the implanted grafts. Generally, non-weight bearing or tip-toe walking with use of a crutch is permitted for 2 postoperative weeks. Partial weight bearing is allowed for two or four postoperative weeks and full weight bearing is possible from the fourth or sixth postoperative week.

The clinical outcome of OAT is relatively favorable. Many studies have shown that the technique was effective in $76-93 \%$ of the patients in achieving clinical improvement. However, there are some factors that could influence the clinical outcome. Jacob et al. ${ }^{41)}$ noted high complication/reoperation rates in patients with large-sized lesions. Seo et al. ${ }^{42)}$ reported that although OAT resulted in good clinical outcome, the improvement was relatively less remarkable in patients who were $\geq 30$ years of age or had $\geq 4.0$ $\mathrm{cm}^{2}$ lesions (Fig. 6).

\section{(2) Osteochondral allograft transplantation}

Osteochondral allograft transplantation can be performed regardless of the size of a lesion and donor site availability and morbidity. The procedure can be employed for treating large lesions, $\geq 10 \mathrm{~cm}^{2}$ in $\mathrm{size}^{433}$. The drawbacks of the procedure include the difficulty of obtaining grafts in a timely manner, 
high cost, and the possibility of immune rejection response and disease transmission ${ }^{44)}$. According to the graft type, there are shell type and deep type allografts. Shell type grafts include $<1$ $\mathrm{cm}$ subchondral bone and deep type grafts include the deeper layer of subchondral bone. According to the graft preservation method, there are fresh allografts, cryopreserved frozen allografts, and fresh frozen allografts. Fresh allografts are stored at $4^{\circ} \mathrm{C}$ and implanted within 1 week of harvesting. Compared to other grafts, fresh allografts have relatively high risk of immune rejection response or disease transmission because it is difficult to completely remove donors' blood from the grafts. Cryopreservation is a process where allografts are preserved in glycerol or dimethyl sulfoxide to minimize chondrocyte death and maintain chondrocyte viability. It is effective for longterm tissue preservation and prevention of immune rejection response and disease transmission, but it has been associated with low survival rates of chondrocytes. Regarding the fresh frozen preservation, grafts are frozen at $-80^{\circ} \mathrm{C}$ immediately after harvesting and accordingly carry low risk of infection or immune response. This procedure costs less than Cryopreservation does. However, chondrocytes are destroyed during freezing and biomechanical properties of extracellular matrix deteriorate over time $^{45,46)}$.

The ideal indications for osteochondral allograft transplantation include traumatic osteoarthritis combined with extensive cartilage defects or subchondral bone defects in active patients, osteochondritis dissecans, and focal avascular necrosis. The contraindications include moderate or severe degenerative arthritis, inflammatory arthritis such as degenerative arthritis, and steroid-induced osteonecrosis ${ }^{47)}$.

Gross et al. ${ }^{48)}$ reported long-term follow-up results of the use of fresh osteochondral allografts for post-traumatic knee defects: the survival rate was $95 \%, 80 \%$, and $65 \%$ at 5,10 , and 15 years after surgery, respectively. According to Ghazavi et al. ${ }^{49)}$ osteochondral allograft transplantation resulted in successful outcome in $85 \%$ and failure in $15 \%$ of the cases at 7.5 years after surgery. Regarding the factors that influence the osteochondral allograft transplantation, Ghazavi et al. ${ }^{49)}$ attributed failure to bipolar tibial and femoral defects, malaligned knees, and workers' compensation status. Osteochondral allograft transplantation can be advantageous in maintaining satisfying results for isolated extensive chondral or ostechondral defects that cannot be managed with OAT or ACI.

\section{Conclusions}

Chondral defects are difficult to treat. Various recent studies have introduced new repair techniques and reported clinical results. However, there is no consensus regarding which method is superior to the others. Factors that should be taken into consideration in determining a surgical method for focal chondral defects include the cause of the defect, concomitant defects, the patient's age and activity level, knee alignment, defect size, cost, and risk of surgery. Degenerative defects cannot be properly managed with surgical repair of articular cartilage. For patients with low activity, arthroscopic debridement is the only

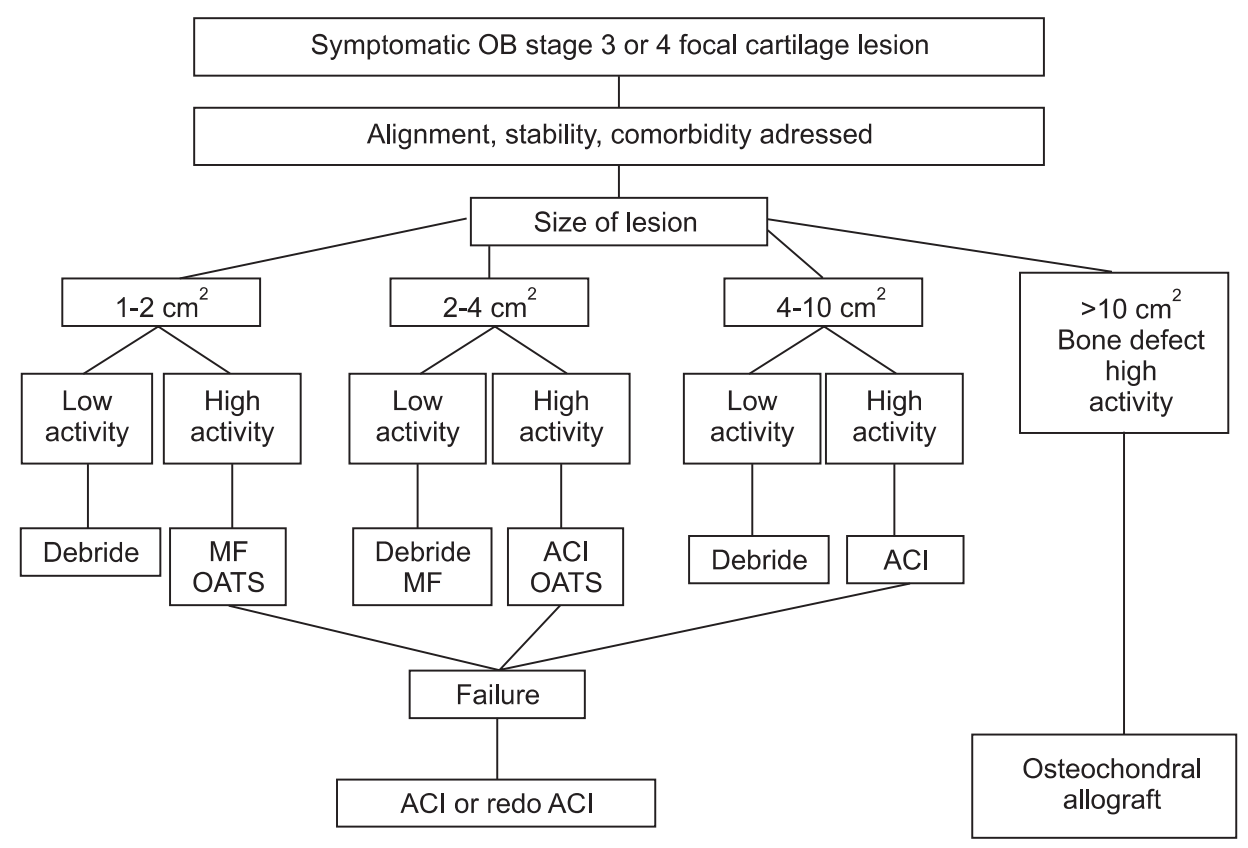

Fig. 7. Treatment algorithm for focal chondral lesions. Before treatment, it is important to assess the presence of correctable lesions (alignment, stability etc.). The treatment decision is guided by the size of the defect and the patient's demands. OB: outerbridge, MF: microfracture, OAT: osteochondral autograft transplantation, ACI: autologous chondrocyte implantation. 
option for knee defects irrespective of the size. Concomitant defects on the affected knee or malalignment should be treated before surgical articular cartilage repair. For lesions that are 1-2 $\mathrm{cm}^{2}$ in size, microfracture or arthroscopic debridement can be a treatment of choice in patients with low activity whereas OAT is effective in patients with high activity. ACI can be a solution when patients with high activity lack sufficient donor sites or microfracture or OAT resulted in failure. For lesions larger than 4 $\mathrm{cm}^{2}$ in size, ACI is the most preferred method and bone grafting should be additionally performed when bone loss is present. Osteochondral defects larger than $10 \mathrm{~cm}^{2}$, focal osteonecrosis, and post-traumatic osteochondral defects are treated with osteochondral allograft transplantation (Fig. 7).

Articular cartilage does not respond well to healing. Damage to the articular cartilage eventually degenerates into arthritis. The goal of current techniques for chondral defects is to prevent the degenerative process by regenerating hyaline like cartilage. Among various methods that have been introduced to achieve this goal, the optimal treatment choice should be based on the understanding of the theoretical backgrounds, indications, surgical technique, rehabilitation, complications, and clinical course of the treatment.

\section{References}

1. Buckwalter JA, Mankin HJ. Articular cartilage. Part II: degeneration and osteoarthrosis, repair, regeneration, and transplantation. J Bone Joint Surg Am. 1997;79:612-32.

2. Shah MR, Kaplan KM, Meislin RJ, Bosco JA 3rd. Articular cartilage restoration of the knee. Bull NYU Hosp Jt Dis. 2007;65:51-60.

3. Curl WW, Krome J, Gordon ES, Rushing J, Smith BP, Poehling GG. Cartilage injuries: a review of 31,516 knee arthroscopies. Arthroscopy. 1997;13:456-60.

4. Craig W, David JW, Ming HZ. A current review on the biology and treatment of the articular cartilage defects (part I \& part II). J Musculoskelet Res. 2003;7:157-81.

5. Messner K, Maletius W. The long-term prognosis for severe damage to weight-bearing cartilage in the knee: a 14-year clinical and radiographic follow-up in 28 young athletes. Acta Orthop Scand. 1996;67:165-8.

6. Guettler JH, Demetropoulos CK, Yang KH, Jurist KA. Osteochondral defects in the human knee: influence of defect size on cartilage rim stress and load redistribution to surrounding cartilage. Am J Sports Med. 2004;32:1451-8.

7. Jackson RW, Gilbert JE, Sharkey PF. Arthroscopic debride- ment versus arthroplasty in the osteoarthritic knee. J Arthroplasty. 1997;12:465-9.

8. Kirkley A, Birmingham TB, Litchfield RB, Giffin JR, Willits KR, Wong CJ, Feagan BG, Donner A, Griffin SH, D’Ascanio LM, Pope JE, Fowler PJ. A randomized trial of arthroscopic surgery for osteoarthritis of the knee. N Engl J Med. 2008;359:1097-107.

9. Steadman JR, Rodkey WG, Rodrigo JJ. Microfracture: surgical technique and rehabilitation to treat chondral defects. Clin Orthop Relat Res. 2001;391 Suppl:S362-9.

10. Tran-Khanh N, Hoemann CD, McKee MD, Henderson JE, Buschmann MD. Aged bovine chondrocytes display a diminished capacity to produce a collagen-rich, mechanically functional cartilage extracellular matrix. J Orthop Res. 2005;23:1354-62.

11. Steadman JR, Rodkey WG, Briggs KK. Microfracture chondroplasty: indications, techniques, and outcomes. Sports Med Arthrosc Rev. 2003;11:236-44.

12. Frisbie DD, Morisset S, Ho CP, Rodkey WG, Steadman JR, McIlwraith CW. Effects of calcified cartilage on healing of chondral defects treated with microfracture in horses. Am J Sports Med. 2006;34:1824-31.

13. Frisbie DD, Oxford JT, Southwood L, Trotter GW, Rodkey WG, Steadman JR, Goodnight JL, McIlwraith CW. Early events in cartilage repair after subchondral bone microfracture. Clin Orthop Relat Res. 2003;(407):215-27.

14. Steadman JR, Miller BS, Karas SG, Schlegel TF, Briggs KK, Hawkins RJ. The microfracture technique in the treatment of full-thickness chondral lesions of the knee in National Football League players. J Knee Surg. 2003;16:83-6.

15. Marder RA, Hopkins G Jr, Timmerman LA. Arthroscopic microfracture of chondral defects of the knee: a comparison of two postoperative treatments. Arthroscopy. 2005;21:1528.

16. Steadman JR, Briggs KK, Rodrigo JJ, Kocher MS, Gill TJ, Rodkey WG. Outcomes of microfracture for traumatic chondral defects of the knee: average 11-year follow-up. Arthroscopy. 2003;19:477-84.

17. Kreuz PC, Steinwachs MR, Erggelet C, Krause SJ, Konrad G, Uhl M, Sudkamp N. Results after microfracture of fullthickness chondral defects in different compartments in the knee. Osteoarthritis Cartilage. 2006;14:1119-25.

18. Mithoefer K, Williams RJ 3rd, Warren RF, Potter HG, Spock CR, Jones EC, Wickiewicz TL, Marx RG. Chondral resurfacing of articular cartilage defects in the knee with the microfracture technique. Surgical technique. J Bone Joint 
Surg Am. 2006;88 Suppl 1 Pt 2:294-304.

19. Mithoefer K, Williams RJ 3rd, Warren RF, Wickiewicz TL, Marx RG. High-impact athletics after knee articular cartilage repair: a prospective evaluation of the microfracture technique. Am J Sports Med. 2006;34:1413-8.

20. Brittberg $M$, Lindahl A, Nilsson A, Ohlsson C, Isaksson O, Peterson L. Treatment of deep cartilage defects in the knee with autologous chondrocyte transplantation. N Engl J Med. 1994;331:889-95.

21. Jones DG, Peterson L. Autologous chondrocyte implantation. Instr Course Lect. 2007;56:429-45.

22. Peterson L, Minas T, Brittberg M, Nilsson A, SjogrenJansson E, Lindahl A. Two- to 9-year outcome after autologous chondrocyte transplantation of the knee. Clin Orthop Relat Res. 2000;(374):212-34.

23. Minas T, Gomoll AH, Rosenberger R, Royce RO, Bryant T. Increased failure rate of autologous chondrocyte implantation after previous treatment with marrow stimulation techniques. Am J Sports Med. 2009;37:902-8.

24. Mithofer K, Peterson L, Mandelbaum BR, Minas T. Articular cartilage repair in soccer players with autologous chondrocyte transplantation: functional outcome and return to competition. Am J Sports Med. 2005;33:1639-46.

25. Saris DB, Vanlauwe J, Victor J, Almqvist KF, Verdonk R, Bellemans J, Luyten FP; TIG/ACT/01/2000\&EXT Study Group. Treatment of symptomatic cartilage defects of the knee: characterized chondrocyte implantation results in better clinical outcome at 36 months in a randomized trial compared to microfracture. Am J Sports Med. 2009;37 Suppl 1:10S-9S.

26. Knutsen G, Engebretsen L, Ludvigsen TC, Drogset JO, Grontvedt T, Solheim E, Strand T, Roberts S, Isaksen V, Johansen O. Autologous chondrocyte implantation compared with microfracture in the knee. A randomized trial. J Bone Joint Surg Am. 2004;86:455-64.

27. Kreuz PC, Steinwachs M, Erggelet C, Krause SJ, Ossendorf C, Maier D, Ghanem N, Uhl M, Haag M. Classification of graft hypertrophy after autologous chondrocyte implantation of full-thickness chondral defects in the knee. Osteoarthritis Cartilage. 2007;15:1339-47.

28. Seo SS, Ha DJ, Kim CW, Kim HJ, Moon SW. Autologous chondrocyte implantation for treating chondral defects of the femoral condyle. J Korean Knee Soc. 2009;21:276-85.

29. Steinwachs M, Kreuz PC. Autologous chondrocyte implantation in chondral defects of the knee with a type I/III collagen membrane: a prospective study with a 3-year follow-up. Arthroscopy. 2007;23:381-7.

30. Gooding CR, Bartlett W, Bentley G, Skinner JA, Carrington $\mathrm{R}$, Flanagan A. A prospective, randomised study comparing two techniques of autologous chondrocyte implantation for osteochondral defects in the knee: Periosteum covered versus type I/III collagen covered. Knee. 2006;13:203-10.

31. Tohyama H, Yasuda K, Minami A, Majima T, Iwasaki N, Muneta T, Sekiya I, Yagishita K, Takahashi S, Kurokouchi K, Uchio Y, Iwasa J, Deie M, Adachi N, Sugawara K, Ochi M. Atelocollagen-associated autologous chondrocyte implantation for the repair of chondral defects of the knee: a prospective multicenter clinical trial in Japan. J Orthop Sci. 2009;14:579-88.

32. Nehrer S, Dorotka R, Domayer S, Stelzeneder D, Kotz R. Treatment of full-thickness chondral defects with hyalograft $\mathrm{C}$ in the knee: a prospective clinical case series with 2 to 7 years' follow-up. Am J Sports Med. 2009;37 Suppl 1:81S-7S.

33. Kim MK, Choi SW, Kim SR, Oh IS, Won MH. Autologous chondrocyte implantation in the knee using fibrin. Knee Surg Sports Traumatol Arthrosc. 2010;18:528-34.

34. Bartlett W, Skinner JA, Gooding CR, Carrington RW, Flanagan AM, Briggs TW, Bentley G. Autologous chondrocyte implantation versus matrix-induced autologous chondrocyte implantation for osteochondral defects of the knee: a prospective, randomised study. J Bone Joint Surg Br. 2005;87:640-5.

35. Zeifang F, Oberle D, Nierhoff C, Richter W, Moradi B, Schmitt $\mathrm{H}$. Autologous chondrocyte implantation using the original periosteum-cover technique versus matrixassociated autologous chondrocyte implantation: a randomized clinical trial. Am J Sports Med. 2010;38:924-33.

36. Hangody L, Rathonyi GK, Duska Z, Vasarhelyi G, Fules P, Modis L. Autologous osteochondral mosaicplasty. Surgical technique. J Bone Joint Surg Am. 2004;86 Suppl 1:65-72.

37. Duchow J, Hess T, Kohn D. Primary stability of press-fitimplanted osteochondral grafts. Influence of graft size, repeated insertion, and harvesting technique. Am J Sports Med. 2000;28:24-7.

38. Whiteside RA, Jakob RP, Wyss UP, Mainil-Varlet P. Impact loading of articular cartilage during transplantation of osteochondral autograft. J Bone Joint Surg Br. 2005;87:128591.

39. Koh JL, Wirsing K, Lautenschlager E, Zhang LO. The effect of graft height mismatch on contact pressure following osteochondral grafting: a biomechanical study. Am J Sports Med. 2004;32:317-20. 
40. Huang FS, Simonian PT, Norman AG, Clark JM. Effects of small incongruities in a sheep model of osteochondral autografting. Am J Sports Med. 2004;32:1842-8.

41. Jakob RP, Franz T, Gautier E, Mainil-Varlet P. Autologous osteochondral grafting in the knee: indication, results, and reflections. Clin Orthop Relat Res. 2002;(401):170-84.

42. Seo SS, Kim CW, Ha DJ, Choi JS, Kim HJ, Lee CR. Autogenous osteochondral grafting for treating osteochondral defect of the femoral condyle of the knee joint. J Korean Orthop Assoc. 2009;44:301-10.

43. Chu CR, Convery FR, Akeson WH, Meyers M, Amiel D. Articular cartilage transplantation. Clinical results in the knee. Clin Orthop Relat Res. 1999;(360):159-68.

44. Bugbee WD, Convery FR. Osteochondral allograft transplantation. Clin Sports Med. 1999;18:67-75.
45. Enneking WF, Mindell ER. Observations on massive retrieved human allografts. J Bone Joint Surg Am. 1991;73:112342.

46. Enneking WF, Campanacci DA. Retrieved human allografts: a clinicopathological study. J Bone Joint Surg Am. 2001;83: 971-86.

47. Hennig A, Abate J. Osteochondral allografts in the treatment of articular cartilage injuries of the knee. Sports Med Arthrosc. 2007;15:126-32.

48. Gross AE, Shasha N, Aubin P. Long-term followup of the use of fresh osteochondral allografts for posttraumatic knee defects. Clin Orthop Relat Res. 2005;(435):79-87.

49. Ghazavi MT, Pritzker KP, Davis AM, Gross AE. Fresh osteochondral allografts for post-traumatic osteochondral defects of the knee. J Bone Joint Surg Br. 1997;79:1008-13. 